\title{
SOBRE A FORMALIDADE DO DEVER MORAL TENDO EM VISTA A DIGNIDADE HUMANA
}

\author{
Tomaz Martins da Silva Filho \\ Professor- IFTO
}

\begin{abstract}
Resumo: Apresenta-se neste artigo a moralidade kantiana como forma de resposta aos anseios da racionalidade prática. De modo que se leva em consideração a necessidade de uma exposição dessa moral tendo em vista o caráter radical do agir, destacando os conceitos de conformidade, desconformidade com o dever. Por fim, analisa-se o dever em sua forma máxima e incondicional, o imperativo categórico, que é em si uma representação do mandamento da razão prática, tendo como objetivo a dignidade humana em sua totalidade como fim e nunca como meio. Tal proposição esclarece o caráter formal do dever minando, assim, o entendimento simplista que julga de forma superficial o desempenho da moralidade kantiana na vida cotidiana.
\end{abstract}

Palavras-chave: Razão; Moralidade; Dever; Formalidade.

Resumen: Presenta en este artículo la moral kantiana como una forma de responder a las aspiraciones de la racionalidad práctica. Toma en cuenta la necesidad de esta moral se muestra a la radicalidad del acto, destacando los conceptos de conformidad, disconformidad con el deber. Por último, se analiza el deber en su máximo expresión incondicional, el imperativo categórico, que es en sí misma una representación de lo mandamento de la razón práctica, con el objetivo de la dignidad humana en su totalidad como un fin y nunca como un medio. Tal proposición aclara el carácter formal del deber socavando así el entendimiento simplista del rendimiento de la moral kantiana en la vida cotidiana.

Palabras clave: Razón; La moralidad; deber; La formalidad.

O conceito de dever é amplamente tratado por Immanuel Kant em sua filosofia prática, visto que constitui a centralidade da moral sustentada na razão. Outrora, vale ressaltar, o conceito de dever constituía heteronomia, pois esteve durante a Antiguidade 
Clássica e a Idade Média atrelado ao princípio da felicidade, seja em um contexto político, como da polis grega, seja de beatitude eterna como na teologia moral. Na Modernidade o dever é resignificado e reestruturado nos moldes da razão. Não se trata, com efeito, de discutir aqui a substancialidade da verdade de tais preceitos morais, mas de propor efetiva discussão em torno da moral do dever que se coloca para além de qualquer moral tendenciosa.

Devido ao curso tomado, o criticismo kantiano sofre a terrível acusação de ser formalista, mecânico, profundamente angelical e, portanto, irrealizável.

Este empreendimento visa tratar descritiva e argumentativamente contra uma visão leviana da moral do dever, que de fato mina qualquer entendimento e direcionamento com vista ao cumprimento da lei moral.

A filosofia kantiana é sistêmica, portanto, não deve ser recortada para uma superficial exposição tradicional, caso o seja, costuma-se incorrer na infidelidade à profundidade dos temas. Em todo caso, aqui, o cerne da questão é o dever e suas máximas levadas à radicalidade da ação filosófica. Deste modo é preciso notar o caráter estrutural do mandamento do dever que é a distinção entre desconformidade, conformidade e ação legitimamente executada por dever que dignifica o homem exigindo o cuidado de si e dos outros. A tarefa árdua de visualizar o homem como sendo a preocupação das ações morais é a superação da oposição adinâmica do comodismo moral, que por sua vez, tem como fundamento o comodismo intelectual, sendo superado pela criticidade de uma razão esclarecida.

A razão moderna, que tem como característica submeter toda gama de conhecimento à crítica, vê-se, na Crítica da Razão Pura (1781) de Kant, obrigada a ser julgada por si mesma. A questão outrora formulada pelos racionalistas e empiristas sobre a gênese do conhecimento verdadeiro já não interessa mais à razão, pois:

Não resta dúvida de que todo o nosso conhecimento começa pela experiência (...) e que, por um lado, originam por si mesmos as representações (...) põem em movimento a nossa faculdade intelectual e levam-na a compará-las, ligá-las ou separá-las, transformando assim a matéria bruta das impressões sensíveis num conhecimento que se denomina (...) experiência e é com esta que todo o conhecimento tem o seu início. (KANT, 2010, p. 36)

Kant põe fim à querela que movimentava o empirismo e o racionalismo, contudo a razão não se satisfaz e submete seus limites à crítica, perguntado sobre seu domínio e percebendo que este se situa no fenômeno, que como tal é "o objeto indeterminado de 
uma intuição empírica”. (KANT, 2010, p. 61). Por indeterminado, deve-se entender tudo aquilo que está na sensibilidade e que não é coisa em si.

Mediante as afirmações feitas acima, percebe-se que a razão enquanto teórica é limitada ao fenômeno, deve, neste caso, projetar-se para a praticidade; a moralidade. Sua tarefa nesse campo é determinar a exequibilidade desta moral que deve estar fundamentada no conceito de dever. Este faz referência à obrigação, portanto, sentir-se obrigado implica dizer que há alguém que o obriga a alguma coisa. Àquele a quem é imposta a obrigação é denominado de legislado, deste modo, o obrigado deve sempre cumprir o dever imposto por quem o legisla.

O legislado é coagido pelo legislador, não age por vontade própria, mas pela vontade do outro. Contudo, por mais rígida que seja a legislação de um sobre o outro, o submisso pode não cumprir a obrigação, segundo $\operatorname{HERRERO~(1991,~p.~21)~o~}$ comportamento do obrigante é: "cego e inumano [...] só obedece quando se apropria dessa lei como lei de sua vontade, isto é, quando dá a si mesmo a lei."

A moral proposta por Kant tem como base o próprio sujeito que executa a ação, ou seja, uma moralidade sustentada simplesmente na razão prática do sujeito que a exerce. Neste sentido ele afirma que tal razão caracteriza-se como: "faculdade que deve exercer influência sobre a vontade, então o seu verdadeiro destino deverá ser produzir uma vontade, não só boa quiçá como meio para uma intenção, mas uma vontade boa em si mesma." (KANT, 2007, p. 25).

A moral kantiana pretende determinar imediatamente à vontade, não dando espaço para o que se chama de inclinação, ou seja, uma vontade externa que impeça o sujeito de viver retamente. Deste modo, "A razão determina imediatamente à vontade, não mediante o sentimento de prazer e desprazer." (KANT, 2002, p. 42), que são todos os desejos que coagem ou estimulam o querer, não tem em vista o fim que ela possa proporcionar, ou desejos individualistas que visam o bem próprio. Portanto, as inclinações compõem a faculdade de apetição inferior.

A vontade que se deixa guiar pela razão prática é chamada de boa vontade pois constituindo a faculdade de apetição superior tem valor em si mesma, ela "não é boa por aquilo que possa promover ou realizar pela aptidão para alcançar qualquer finalidade proposta, mas tão somente pelo querer, isto é, em si mesma." (KANT, 2007, p. 204).

A boa vontade é, portanto, a faculdade de querer que deve ser guiada pela razão e, por isso, não deve se sentir obrigada por nada que esteja fora do sujeito ao qual ela 
pertence. Há na moral kantiana uma proposta ao homem impregnando por interesses próprios, o uso de sua razão no plano prático, pois acredita Kant que: “[...] quanto mais uma razão cultivada se consagra ao gozo da vida e da felicidade, tanto mais o homem se afasta do verdadeiro contentamento.” (KANT, 2007, p. 24). A razão do homem deve, sobretudo, servir como parâmetro para suas ações, mas nunca para promovê-lo sobre os outros, assim proporcionando-lhe felicidade individualista.

Uma vez que o homem se dispõe através da razão a auto legislar faz-se necessário haver algum princípio a partir do qual ele deva agir corretamente com relação às leis morais impostas pela mesma razão legisladora. E este princípio é o do dever que toma como ponto de partida a boa vontade.

O sujeito que queira ser moral, segundo Kant, deve agir guiado pela razão, e, portanto, praticando sempre a moral do dever. E dever em Kant: "é a necessidade de uma ação por respeito à lei." (KANT, 2007, p. 31). A lei que se deve respeitar é sempre a da própria razão prática que governa a vontade para que ela não seja apetição inferior, mas sim, auto legislação. Por sua vez, auto legislar-se é seguir os mandamentos da razão em vista de ser simplesmente cumprido, por se tratar de uma obrigação universal que:

[...] tem seu valor moral, não no propósito que com ela se quer atingir, mas na máxima que a determina; não depende, portanto da realidade do objeto da acção, mas somente do princípio do querer segundo a qual a acção, abstraindo de todos os objetos da faculdade de desejar, foi praticada. (KANT, 2007, p. 30, grifo do autor).

O dever é a ação moral que a razão exige do sujeito mediante o uso de uma máxima que mesmo propensa a inclinações tem destaque de tal modo que pode se tornar um princípio universal, pelo fato de se fundamentar na boa vontade, que é o princípio do querer. Mas, a questão que se põe diante do exposto é: como pode uma máxima, que é um princípio subjetivo, ser um dever? Para que se compreenda o que diferencia uma máxima fundamentada na boa vontade e outra que é fundamentada nas inclinações é preciso distinguir o agir por dever, do agir conforme o dever. Eis uma tarefa que segundo Kant não é fácil, pois quando se pensa que um sujeito age por dever ele pode muito bem estar agindo apenas em conformidade. Então, em que consiste a conformidade com o dever?

A conformidade com o dever consiste em dissimular uma ação moral, onde todos pensam que o sujeito age guiado por sua razão, na verdade ele age por inclinações que: 
por amável que seja, não tem contudo nenhum verdadeiro valor moral, mas vai emparelhar-se com outras inclinações, por exemplo o amor das honras que, quando por feliz acaso topa aquilo que efectivamente é de interesse geral e conforme ao dever, é consequentemente honroso e merece louvor e estímulo, mas não estima; pois sua máxima falta o conteúdo moral que manda tais ações se pratiquem, não por inclinação, mas por dever. (KANT, 2007 , p. 28, grifo do autor).

A benfeitoria para com o próximo é sem dúvida digna de honra e aparentemente moral, mas quando se sabe que esta ou aquela ação foi executada por medo ou por esperança, amor ou vingança, em nada tem valor, porque foi executada por inclinação, conclui-se que a ação está apenas em simples conformidade com o dever.

É uma tarefa por demais perigosa julgar as ações dos outros e defini-las como conforme ou por dever, pois nenhum homem perscruta o coração do outro. Porém, fazer essa definição cabe ao próprio sujeito que exerce a ação, pois só ele sabe o que ocorre em seu íntimo.

Definida o que é uma ação conforme ao dever, cabe aqui conceituar o que é uma ação praticada por dever. Esta ocorre por um processo simples onde o sujeito olha seu íntimo e questiona a si próprio:

Ficaria eu satisfeito de ver minha máxima [...] tomar valor de lei universal? E poderia eu dizer a mim mesmo: toda gente pode fazer uma promessa mentirosa quando acha uma dificuldade de que não pode sair de outra maneira? Em breve reconheço que posso em verdade querer a mentira, mas que não posso querer uma lei universal de mentir. (KANT, 2007, p. 34).

A máxima pode ou não estar ligada à subjetividade, portanto, é possível ou não tirar proveito individual dela, todavia haverá dever, se de fato ela for passível de universalização. Não há meio do sujeito querer a universalização de alguma inclinação, pois alguém dotado de reta razão pode sem dúvida querer o princípio subjetivo, mas nunca torná-lo universal, pois sendo ele esperto não desejará mau para si próprio, tornando-se vítima da própria artimanha. Assim, a ação por dever é extremamente racional, pois não se baseia em qualquer inclinação que esteja ligada ao amor de si, visto que:

Todas as inclinações em conjunto (certamente podem ser também compreendidas em um razoável sistema e cuja satisfação chama-se então felicidade própria) constituem o solipsismo. Este consiste ou no solipsismo do amor de si, como uma benevolência consigo 
mesmo sobre todas as coisas (philautia), ou no solipsismo da complacência em si mesmo (arrogância). (KANT, 2002, p. 117118 , grifo do autor).

O dever abomina todo tipo de apetição inferior, que consistem basicamente no individualismo, no amor de si, estimulando o hedonismo. Nas inclinações entram o ódio, o prazer, a benevolência, a amizade e o amor ${ }^{1}$ e todo e qualquer sentimento que queira se tornar princípio de uma máxima que deseja determinar a vontade.

Algumas inclinações, mesmo estando em conformidade com o dever, não virão a configurá-lo, pois tem como base o interesse individual ou por qualquer outro móbile externo. A ação por dever exige uma cisão com as inclinações, fazendo desta forma o subjugo delas à lei da razão, bem como, não haverá espaço também para a legalidade da ação, mas somente para a moralidade. Não interessa ao dever o fim que possa proporcionar a ação guiada pela inclinação - se este será bom ou não - nem o meio, pois é sempre ignorável por se tratar de um mobile externo. Deste modo, agir por dever consiste simplesmente em agir com base em uma razão legisladora.

Quando se fala em legalidade da ação diferenciando-a da moralidade, se reporta àquela própria dos códigos morais, sejam os canônicos de cunho religioso ou a lei civil, que estando ou não em acordo com o dever, constitui uma obrigação externa e por isso é desinteressante para a legislação racional prática.

O essencial de todo o valor moral das ações depende de que a lei moral determine imediatamente a vontade. Com efeito, se a determinação da vontade acontecer conforme a lei moral, mas somente através de um sentimento, seja ele de que espécie for e que tenha de ser proposto para que a lei moral se torne fundamento determinante suficiente da vontade, por conseguinte não por causa da lei, nesse caso a ação moral em verdade conterá legalidade, mas não moralidade. (2002, p. 114)

Na obediência da lei externa civil e não interiorizada, há conformidade, mas não a racionalidade prática. $\mathrm{O}$ dever até o momento não tomou como base, se não a vontade que pode ser boa, mas também pode se corromper, através dos móbiles externos. É preciso determinar imediatamente à vontade através de imperativos, afim de que garantam resultados necessários aos interesses seja da razão.

1 Quando se refere aqui em amor se trata de amor patológico e não do amor prático que toma como fundamento o dever, este traz em si o cuidado pelo outro como seu semelhante, pois identifica-se como partícipe da mesma natureza, devendo reconhecer-se incapaz de feri-lo, mesmo diante de oportunidade concebível. 
A necessidade de algo que represente o mandamento da razão fez com que Kant em uma obra chamada Fundamentação da Metafísica dos Costumes publicada em 1785, passasse do uso vulgar do dever para o uso filosófico de uma metafísica dos costumes, visto que pode haver, como fora dito anteriormente, uma confusão quanto à ação moral do sujeito:

que ainda a maior parte das nossas ações são conformes ao dever; mas examinemos mas de perto as suas aspirações e esforços, toparemos por toda parte o querido Eu que sempre sobressai, e é nele, e não no severo mandamento do dever que muitas vezes exigiria a auto-renúncia, que a sua intenção se apóia. (KANT, 2007 , p. 41, grifo do autor).

Kant reconhece a realidade do homem enquanto sujeito que mesmo sendo capaz de atingir via moral o númeno ${ }^{2}$ é ainda limitado ao mundo da experiência sensível, caracterizado pela experiência empírica que no campo moral se expressa pela conformidade com a ação por dever na legalidade. A conformidade com o dever ou a legalidade da ação do sujeito com relação a uma lei positiva ${ }^{3}$ acontece pelo fato de que a vontade humana não é inteiramente submetida à obrigação do dever.

Quando uma ação ocorre conforme ao dever é em todo caso porque a vontade é apenas conforme a razão, mas nunca submissa à mesma. A razão, por seu turno, determina a vontade à medida que é faculdade do querer. No entanto, por força das inclinações e da limitação do homem, esta pode desviar-se de sua finalidade.

Quanto a essa limitação do homem é pelo fato do mesmo interpretar mal o que é uma ação moral, pois ele não sabe que: “[...] quando se fala de valor moral, não é das acções visíveis que se trata, mas dos seus princípios íntimos que se não veem." (KANT, 2007 , p. 40, grifo do autor), por isso ele age apenas conforme ao dever, ou por legalidade. Dada a situação deve-se considerar que:

Só um ser racional tem a capacidade de agir segundo a representação das leis, isto é, segundo princípios, ou: só ele tem uma vontade [...] [que] é a faculdade de escolher só aquilo que a razão, independentemente da inclinação, reconhece como praticamente necessário, quer dizer como bom. (KANT, 2007, p. 47).

\footnotetext{
${ }^{2}$ A coisa em si, por oposição ao fenômeno, é o objeto intelectual desprovido de qualquer relação com a sensibilidade.

3 O termo positivo indica a lei externa ao sujeito transcendental, a lei canônica - é a lei enquanto estatuto seja civil ou eclesiástico. 
O homem é portador da faculdade do querer, de uma vontade que se rege por sua própria razão. Todavia, já fora dito, que a razão não determina imediatamente a vontade, pois pode sentir-se obrigada ou não. Deste modo, é preciso que o homem haja segundo representações do mandamento e não simplesmente pelo princípio do dever, que enquanto "princípio objectivo, obrigante para uma vontade, chama-se mandamento (da razão), e a fórmula do mandamento chama-se Imperativo [...] Todos os imperativos se exprimem pelo verbo dever. " (KANT, 2007, p. 48, grifo do autor).

Deve-se fazer a distinção entre a representação do princípio do dever em si e a matéria do dever. Quando se age pela representação do dever, se age pelo imperativo e não simplesmente pela matéria que possa infiltrar-se no princípio do dever. A matéria em voga é o objeto que se quer atingir mediante um interesse subjetivo, ou seja, aquilo que é objetivado de acordo com o interesse individual. Já a forma é aquela parte do dever que dita universalmente; é a lei, o mandamento que quer legislar. Assim, a representação, a que se chama de imperativos podem ordenar de duas formas:

[...] ordenam ou hipotética- ou categoricamente. Os hipotéticos representam a necessidade prática de uma acção possível como meio de alcançar qualquer outra coisa que se quer (ou o que é possível que se queira). O imperativo categórico seria aquele que nos representasse uma acção como objectivamente necessária por si mesma, sem relação com qualquer outra finalidade. (KANT, 2007, p. 50, grifo do autor).

A diferença entre os dois imperativos consiste necessariamente no fato de que o imperativo hipotético exerce determinada ação em vista de um fim, que não é a própria ação, estão sempre ligados àquele caráter fenomênico do homem não constituindo assim a forma da representação universal do dever. Portanto, é recusável para um uso formal assim como as ações conformes ao dever trazem consigo finalidades. Apesar de serem formas do princípio de moralidade os hipotéticos ainda são contaminados por um interesse individual.

No que diz respeito ao imperativo categórico este sim é considerado: "o imperativo da moralidade." (KANT, 2007, p. 52). Visto que é a representação máxima do dever se cumpre incondicionalmente o mandamento da razão prática. Expressa a universalidade da lei moral do dever, nele não se busca um fim externo, como no caso do hipotético, mas o único fim é ele próprio, pois tal imperativo se formula deste modo: "Age de tal modo que a máxima de tua vontade possa sempre valer ao mesmo tempo como princípio de uma legislação universal." (KANT, 2002, p. 51). Nesta formulação 
do imperativo categórico não há de modo algum espaço para o amor de si, pois deve o homem obrigatoriamente por sua razão fazer todas as suas máximas princípios universais, se quiser ser considerado como sujeito moral.

O caráter incondicional do imperativo categórico ocorre pelo fato dele não se filiar a coisa alguma já que tem sustentação em si mesmo. A única finalidade deste imperativo é a si próprio, pois mostra deste modo que o interesse da Crítica da Razão Prática (1788) é simplesmente o homem enquanto sujeito moral.

É necessário considerar tudo que fora afirmado sobre o imperativo categórico para que se possa conceber o homem como ente racional moral, pois é por meio da representação universal do dever pode ser considerado possuidor de razão prática legisladora. Ora, ter uma razão auto reguladora é conceber que nada de fenomênico possa causar dano à moralidade prática estabelecida que as inclinações em nada poderão influenciar. Isto é o processo de autonomia visto que o homem se torna como tal, pelo fato de não depender de nada relacionado à cadeia de causas e efeitos, própria da natureza.

Conclui-se do que foi exposto que o interesse da razão prática é um homem como fim em si mesmo, que se apresentando como tal, se mostre também em estado de liberdade. Essa liberdade só ocorre mediante a autonomia da vontade concebida em âmbito prático.

O processo de autonomia do homem é consequência da ação moral respaldada no imperativo categórico que expressa a teleologia da moralidade do dever, ganhando este caráter formal. Assim, é justo falar de rigidez do dever moral por sua formalidade. Por vezes, tais conceitos são mal interpretados, levando a crer que a filosofia kantiana é legalista. O legalismo civil e o rigorismo religioso ao contrário prejudicam a execução da lei moral prática que só tem realização plena na livre adesão à representação do mandamento do dever.

Deste modo, o dever é radical e inflexível quando aderido enquanto máxima da razão, mas nunca opressor do ser humano que o executa, pois não se pode ferir a humanidade com o cuidado e o zelo por ela própria. A formalidade do dever sempre prima pelo cuidado com o outro. Cada homem traz consigo a humanidade, não devendo fazer nem a si, nem a outros como meios, mas fins completos de dignidade, manifestando a representação do dever. 


\section{Referências}

HERRERO, Francisco Javier. Religião e história em Kant. Tradução José A. Ceschia. São Paulo: Loyola, 1991.

HÖFFE, Otfried. Immanuel Kant. Tradução Chistian Viktor Hamn, Valério Rohden. São Paulo: Martins Fontes, 2005.

Kant, Immanuel. Crítica da razão prática. Trad. Valério Rohden. São Paulo: Martins Fontes, 2002.

Crítica da razão pura. Trad. Manuela dos Santos e Alexandre Morujão. $7^{\mathrm{a}} \mathrm{ed}$. Lisboa: Fundação Calouste Gulbenkian, 2010.

Fundamentação da metafísica dos costumes. Trad. Paulo Quintela. Lisboa: Edições 70, 2007. 